\title{
Metformin-activated AMPK regulates $\beta$-catenin to reduce cell proliferation in colon carcinoma RKO cells
}

\author{
SONG YI PARK, DASARANG KIM and SUN-HO KEE \\ Department of Microbiology, College of Medicine, Korea University, Seoul 136-705, Republic of Korea
}

Received July 6, 2018; Accepted December 7, 2018

DOI: $10.3892 / 01.2019 .9892$

\begin{abstract}
Metformin can suppress cell proliferation and viability by altering mitochondrial energy metabolism and by the activation of 5'-adenosine monophosphate-activated protein kinase (AMPK). The current study demonstrated that metformin-induced suppression of cell proliferation is further potentiated by AMPK-mediated suppression of $\beta$-catenin-dependent wingless-type (Wnt) signaling. Treatment with metformin reduced mitochondrial oxidative phosphorylation and glycolysis, leading to an energy imbalance that may induce AMPK phosphorylation in RKO cells. Metformin treatment also decreased $\beta$-catenin expression in the cytoplasm and nucleus. Active AMPK was revealed to be associated with $\beta$-catenin. The decrease in $\beta$-catenin expression was inhibited by proteosome inhibition through phosphorylation of $\beta$-catenin at serine 33/37. Given that nuclear translocation-associated phosphorylation of $\beta$-catenin at serine was maintained, the association of $\beta$-catenin with AMPK may sequester $\beta$-catenin in the cytoplasm and lead to proteosomal degradation. Furthermore, metformin-induced suppression of cell proliferation was partially recovered by AMPK inhibition, while metformin inhibited Wnt-mediated cell proliferation and $\beta$-catenin expression. The present results suggest that AMPK activation can suppress $\beta$-catenin-dependent Wnt signaling by cytoplasmic sequestering of $\beta$-catenin through AMPK, which further decreases cell proliferation in addition to metformin-induced mitochondrial dysfunction.
\end{abstract}

\section{Introduction}

The most notable trait of cancer cells is their marked survival advantage compared with normal cells, which allows them to continue proliferating despite apoptotic signals. In this context,

Correspondence to: Professor Sun-Ho Kee, Department of Microbiology, College of Medicine, Korea University, 73 Inchon-Ro, Seongbuk, Seoul 136-705, Republic of Korea

E-mail: keesh@korea.ac.kr

Key words: 5'-adenosine monophosphate-activated protein kinase, $\beta$-catenin, metformin, adenosine 5'-triphosphate production, cell proliferation wingless-type (Wnt) signaling is understood to serve a pivotal role in connecting extracellular survival signals and intracellular apoptotic signals. Hyperactivation of Wnt signaling is frequently observed in numerous types of carcinomas (1-3). $\beta$-catenin is a major transcription factor in the Wnt signaling pathway that is also responsible for controlling cell-cell adhesion through intracellular binding with $\alpha$-catenin and E-cadherin (4). When Wnt signaling is activated, $\beta$-catenin translocates to the nucleus to promote cell proliferation and induce tumor cell migration, invasion and metastasis through loss of cell-cell contacts (5).

5'-Adenosine monophosphate-activated protein kinase (AMPK) is a serine/threonine kinase understood to function as an energy sensor to maintain cellular-energy homeostasis by inhibiting energy-consuming anabolic pathways and activating energy-generating catabolic energy pathways when a cell is depleted of energy (6). When cells are exposed to stress, cellular adenosine 5'-triphosphate (ATP) consumption is increased and AMPK is activated, thereby inducing apoptosis (7). AMPK has also attracted attention as an important tumor suppressor due to its association with a number of molecules, including liver kinase B1 (LKB1) and tuberous sclerosis (8,9). Furthermore, AMPK has been examined for its role as a cancer regulator, as LKB1 is an upstream activator of AMPK in colon cancer cells (10).

Metformin can block gluconeogenesis and inhibit metabolic syndromes by activating AMPK in the liver, implying that it may be useful for treating type 2 diabetes (11). A previous study has demonstrated that metformin may be used as a cancer therapy, as it can inhibit mitochondrial complex I for cellular energy production and induce apoptosis (12). Metformin-mediated reduction of cellular energy production promotes AMPK activation, and activated AMPK can suppress cancer cell proliferation and cause cancer cell death by inhibiting cancer cell growth signaling pathways, particularly the mechanistic target of rapamycin (mTOR) and Wnt signaling pathways (13). However, to the best of our knowledge, the detailed mechanism regarding the inhibitory effect of metformin on cell proliferation is currently unclear. Therefore, the objective of the present study was to determine whether active AMPK could bind to $\beta$-catenin and suppresses Wnt signaling, thus potentiating metformin-induced suppression of cell proliferation.

\section{Materials and methods}

Cells and reagents. Human colon carcinoma RKO cells were purchased from the American Type Culture Collection 
(Manassas, VA, USA) and cultured in Dulbecco's modified Eagle's medium (Serana Europe GmBH, Pessin, Germany) containing $10 \%$ fetal bovine serum (Biotechnics Research, Inc., Lake Forest, CA, USA; catalog no. 7101). Metformin was obtained from Sigma-Aldrich; Merck KGaA (Darmstadt, Germany; catalog no. D150959). Compound C (catalog no. 171260) and MG132 (catalog no. 474790) were purchased from EMD Millipore (Billerica, MA, USA). Wnt3a was purchased from R\&D Systems Inc. (Minneapolis, MN, USA; catalog no. 5036-WN).

Cell proliferation measurement. Cells were seeded into 96-well microplates at a density of $1 \times 10^{4}$ cells/well and incubated with $0,0.05,0.1,0.5,1,2.5,5,10$ or $20 \mathrm{mM}$ metformin for $24 \mathrm{~h}$ at $37^{\circ} \mathrm{C}$ in an atmosphere containing $5 \% \mathrm{CO}_{2}$. Following incubation with the test compound, the medium was removed and the cells were incubated with $5 \mu 1$ MTT solution $(5 \mathrm{mg} / \mathrm{ml}$ MTT in PBS) for $1 \mathrm{~h}$ followed by solubilization in dimethyl sulfoxide. The purple formazan dye converted from MTT by viable cells was quantified by measuring the absorbance at a wavelength of $595 \mathrm{~nm}$.

The 5-bromodeoxyuridine (BrdU) incorporation assay was performed using a BrdU Cell Proliferation ELISA kit (Roche Applied Science, Rotkreuz, Switzerland), according to the manufacturer's protocol. Absorbance at $370 \mathrm{~nm}$ was measured using an ELISA reader (SpectraMax plus 384; Molecular Devices, LLC, Sunnyvale, CA, USA).

ATP assay. Intracellular ATP levels were measured using a Luminescence ATP Detection assay system (ATPlite; PerkinElmer, Inc., Waltham, MA, USA, catalog no. 6016941), according to the manufacturer's protocol. Cells were cultured into 96-well microplates at a density of $1 \times 10^{4}$ cells/well for $16 \mathrm{~h}$ at $37^{\circ} \mathrm{C}$. The cells were then treated with $100 \mu \mathrm{l}$ culture medium containing $0,5,10$ or $20 \mathrm{mM}$ metformin for $24 \mathrm{~h}$ at $37^{\circ} \mathrm{C}$. After $24 \mathrm{~h}$ of incubation, $50 \mu \mathrm{l}$ mammalian cell lysis solution from the Luminescence ATP Detection assay system was added to each well and the plate was placed in an orbital shaker at $55 \mathrm{x} \mathrm{g}$ for $5 \mathrm{~min}$. Subsequently, $50 \mu \mathrm{l}$ substrate solution from the Luminescence ATP Detection assay system was added and the plate was placed in an orbital shaker at $55 \mathrm{xg}$ for $5 \mathrm{~min}$. ATP amount was normalized by the cell number, which was assessed by BrdU assay.

Immunoblotting. RKO cells were washed with ice-cold PBS. Total protein was then extracted using protein lysis buffer (20 mM HEPES-KOH (pH 7.4), 1 mM EGTA, $50 \mathrm{mM} \mathrm{KCl}$ and $2 \mathrm{mM} \mathrm{MgCl}_{2}$ ) with protease inhibitor cocktail and $1 \mathrm{mM}$ dithiothreitol. The protein concentration was determined with a DC protein assay (Bio-Rad Laboratories, Inc., Hercules, CA, USA; catalog no. 500-0113). Proteins (10 $\mu \mathrm{g})$ were loaded on 9\% SDS-PAGE gels and then electrophoretically transferred to polyvinylidene fluoride membranes. The membranes were blocked with $10 \%$ skim milk at room temperature for $1 \mathrm{~h}$. The proteins were then subjected to immunoblot analysis using specific antibodies. Primary antibodies were added at $4^{\circ} \mathrm{C}$ for $16 \mathrm{~h}$, followed by horseradish peroxidase-conjugated secondary antibodies, including goat anti-rabbit IgG (Bio-Rad Laboratories, Inc.; 1:3,000; catalog no. 170-6515) or goat-anti-mouse IgG (Bio-Rad Laboratories, Inc.; 1:3,000; catalog no. 172-1011) at room temperature for $1 \mathrm{~h}$. Proteins were visualized using enhanced chemiluminescent reagent (PerkinElmer, Inc; catalog no. NEL120001EA). The following primary antibodies were used: phosphorylated (p)-AMPK $\alpha 1$ (Thr172) (1:1,000; catalog no. 2535s; Cell Signaling Technology, Inc., Danvers, MA, USA), p- $\beta$-catenin (Ser33/37) (1:500; catalog no. 9561s; Cell Signaling Technology, Inc.), p- $\beta$-catenin (Ser552) (1:1,000; catalog no. 9566s; Cell Signaling Technology, Inc.), $\beta$-catenin (1:1,000; catalog no. 610154; BD Biosciences, San Jose, CA, USA), lamin A/C (1:1,000; catalog no. 612163; BD Biosciences), AMPK $\alpha 1 / 2$ (1:1,000; catalog no. sc-74461; Santa Cruz Biotechnology, Inc., Dallas, TX, USA); $\beta$-actin (1:1,000; catalog no. sc-sc-47778; Santa Cruz Biotechnology, Inc.) and GAPDH (1:1,000; catalog no. sc-32233; Santa Cruz Biotechnology, Inc.).

Measurement of oxygen consumption rate (OCR). RKO cells were plated into XF24 cell culture microplates (Seahorse Bioscience, North Billerica, MA, USA) at a density of 20,000 cells/well. The cells were then treated with $10 \mathrm{mM}$ at $37^{\circ} \mathrm{C}$ in an atmosphere containing $5 \% \mathrm{CO}_{2}$. Following $24 \mathrm{~h}$ of treatment, the cell culture growth medium in the microplate was replaced with warmed Seahorse XF base medium (catalog no. 102353-100; Seahorse Bioscience) using a multichannel pipette. Oligomycin $(2 \mu \mathrm{M}), \mathrm{FCCP}(0.1 \mu \mathrm{M})$, antimycin A $(1 \mu \mathrm{M})$ and rotenone $(1 \mu \mathrm{M})$, from the Agilent Seahorse XF Cell Mito Stress Test kit (Agilent Technologies, Inc., Santa Clara, CA, USA; catalog no. 103015-100) were then consecutively added to the each well. The cells were then incubated at $37^{\circ} \mathrm{C}$ in an incubator with $0 \% \mathrm{CO}_{2}$ for $45 \mathrm{~min}$ to $1 \mathrm{~h}$ prior to the assay. OCR was measured using an XF24 Analyzer (Seahorse Bioscience). Measured values were normalized by cell number, which was assessed by BrdU assay.

Immunofluorescence. Cells were seeded onto cover glasses in a 12-well plate. After $16 \mathrm{~h}$ the cells were treated with $10 \mathrm{mM}$ metformin at $37^{\circ} \mathrm{C}$ in an atmosphere containing $5 \% \mathrm{CO}_{2}$. After $24 \mathrm{~h}$, the cells were fixed with $4 \%$ paraformaldehyde for $10 \mathrm{~min}$ and permeabilized in $0.1 \%$ Triton X-100 for $20 \mathrm{~min}$ at room temperature. Cells were then blocked with $2 \%$ bovine serum albumin for $1 \mathrm{~h}$ at room temperature and incubated at $4^{\circ} \mathrm{C}$ overnight with primary antibodies against AMPK and $\beta$-catenin. Following washing, cells were incubated with fluorochrome-conjugated anti-mouse (1:200; catalog no. TI-2000) and anti-rabbit IgG (1:100; catalog no. FI-1000; both from Vector Laboratories, Inc., Burlingame, CA, USA) at room temperature for $1 \mathrm{~h}$. Subsequently, nuclei were stained with $10 \mu \mathrm{M}$ Hoechst 33342 (Invitrogen; Thermo Fisher Scientific, Inc.; catalog no. H1399) for $10 \mathrm{~min}$ at room temperature, and visualized using a fluorescence microscope (magnification, $\mathrm{x} 400)$ and a digital camera.

Immunoprecipitation. Cells were cultured in a $100 \mathrm{~mm}$ culture dish for $24 \mathrm{~h}$ and then treated with $10 \mathrm{mM}$ metformin for $24 \mathrm{~h}$ at $37^{\circ} \mathrm{C}$ in an atmosphere containing $5 \% \mathrm{CO}_{2}$. Cells were harvested by centrifugation at $1,000 \mathrm{xg}$ at $4^{\circ} \mathrm{C}$ for $10 \mathrm{~min}$, washed with PBS, and lysed with protein lysis buffer. Cell extracts were then incubated with Protein $\mathrm{G}$ agarose beads at $4^{\circ} \mathrm{C}$ for $3 \mathrm{~h}$. Following washing with lysis buffer three times, extracts were incubated with an anti-AMPK $\alpha 1 / 2$ antibody at $4^{\circ} \mathrm{C}$ overnight. 


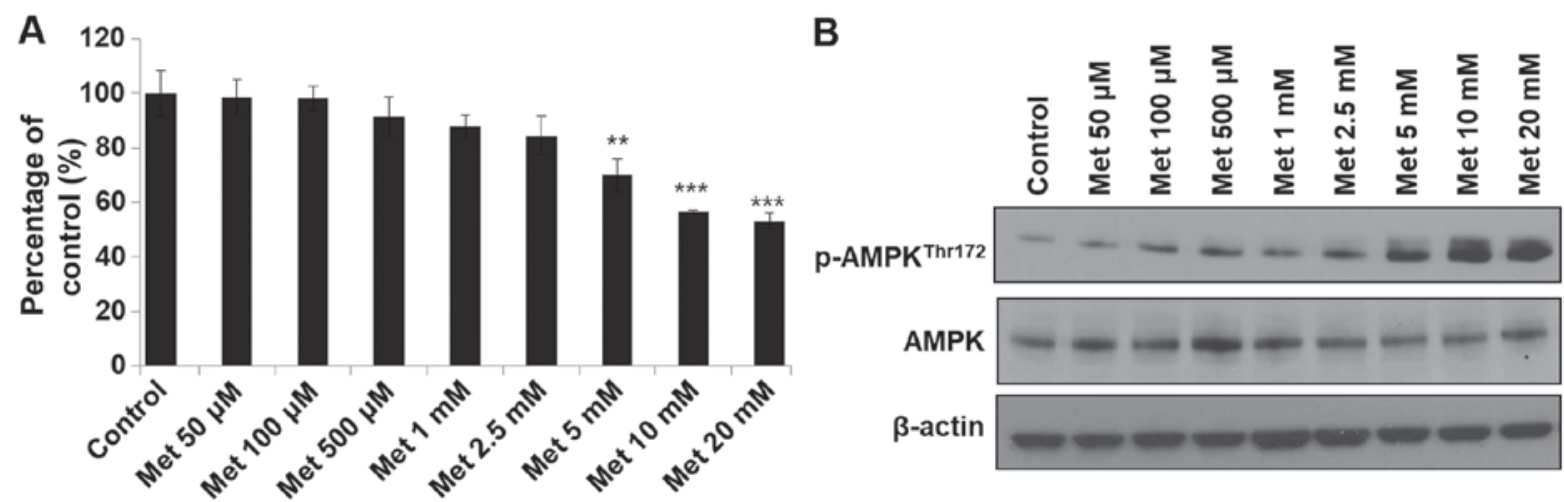

Figure 1. Metformin inhibits RKO cell proliferation at high concentrations. (A) Cells were treated with metformin at different concentrations (50 $\mu \mathrm{M}$ to $20 \mathrm{mM}$ ) for $24 \mathrm{~h}$ and cell viability was measured by MTT assay. (B) Cell lysates were subjected to immunoblot analysis for p-AMPK, AMPK and $\beta$-actin. ${ }^{* *} \mathrm{P}<0.01$ and ${ }^{* * * *} \mathrm{P}<0.001$ vs. control by one-way analysis of variance followed by Duncan's test. Met, metformin $\mathrm{p}$, phosphorylated; AMPK, 5 '-adenosine monophosphate-activated protein kinase.

Following washing with lysis buffer, SDS-loading buffer containing $\beta$-mercaptoethanol was added and the samples were boiled for $5 \mathrm{~min}$. The proteins [whole cell lysate (WCL), $10 \mu \mathrm{g}$; and immunoprecipitation (IP), $10 \mu \mathrm{l}]$ were loaded on 9\% SDS-PAGE gels and then electrophoretically transferred to polyvinylidene fluoride membranes. Subsequently, the membranes were blocked with $10 \%$ skim milk at room temperature for $1 \mathrm{~h}$. The proteins were then subjected to immunoblot analysis using AMPK $1 / 2 \alpha, \beta$-catenin and $\beta$-actin antibodies. Primary antibodies were added for $16 \mathrm{~h}$ at $4{ }^{\circ} \mathrm{C}$ followed by horseradish peroxidase-conjugated goat-anti-mouse $\operatorname{IgG}$ secondary antibodies (Bio-Rad Laboratories, Inc.; 1:3,000; catalog no. 172-1011) at room temperature for $1 \mathrm{~h}$. Proteins were visualized using enhanced chemiluminescent reagent (PerkinElmer, Inc; catalog no. NEL120001EA).

Statistical analysis. Data are presented as the mean \pm standard deviation. All data were analyzed using SPSS 20.0 software (IBM Corp., Armonk, NY, USA). Comparisons between groups were performed using Student's t-test or one-way analysis of variance followed by Duncan's multiple-range test. $\mathrm{P}<0.05$ was considered to indicate a statistically significant difference. All experiments were conducted in triplicate.

\section{Results}

Metformin suppresses cell proliferation and ATP production, resulting in AMPK activation. The effects of metformin on cell proliferation and energy production in colon cancer RKO cells were examined. RKO cells were treated with metformin at low to high concentrations for $24 \mathrm{~h}$. AMPK activation was observed in the groups treated with metformin at $100 \mu \mathrm{M}$ to $20 \mathrm{mM}$ and cell growth inhibition was observed in groups treated with 5-20 mM metformin (Fig. 1). Therefore, the concentrations of metformin that effectively activated AMPK and inhibited cell growth were selected for further experiments. Treatment with metformin at different concentrations (5-20 mM) for $24 \mathrm{~h}$ significantly inhibited RKO cell viability (Fig. 2A and B) and reduced ATP production (Fig. 2C). Subsequent analysis demonstrated that metformin increased the expression level of pAMPK, but decreased the expression level of $\beta$-catenin (Fig. 2D). AMPK is a master regulator of cellular energy homeostasis (6); therefore, AMPK may be activated by the reduction of cellular ATP. Several types of cancer cell have demonstrated increased energy metabolism through glycolysis and/or oxidative phosphorylation with increased production of ATP (14). In metformin-treated RKO cells in the present study, mitochondrial oxidative phosphorylation and glycolysis were reduced compared with that in the controls (Fig. 2E and F).

Metformin suppresses $\beta$-catenin nuclear translocation involving binding of AMPK with $\beta$-catenin. $\beta$-catenin is a major effector of Wnt signaling as it transcriptionally regulates the expression of c-myc, c-Jun and cyclin D1 to increase cell proliferation and oncogenesis (15). Upon activation of Wnt signaling, $\beta$-catenin binds to Tcf and translocates into the nucleus (16). The suppression of $\beta$-catenin translocation by metformin was evaluated according to the status of AMPK activity (Fig. 3). Treatment with metformin decreased nuclear $\beta$-catenin expression, according to immunoblotting and immunofluorescence assays (Fig. 3A and C), which suggests that a decrease of cytosolic $\beta$-catenin resulted in $\beta$-catenin nuclear translocation. A subsequent immunoprecipitation assay demonstrated the association between AMPK and $\beta$-catenin following metformin treatment. Co-localization of AMPK with $\beta$-catenin was confirmed (Fig. 3B and C). These results suggest that AMPK can bind to $\beta$-catenin in the cytosol and such binding may suppress translocation of $\beta$-catenin into the nucleus.

Metformin-induced AMPK activation leads to $\beta$-catenin degradation. Cytoplasmic $\beta$-catenin is complexed with adenomatous polyposis coli, axin and glycogen synthase kinase (GSK), and subjected to proteasomal degradation following GSK-mediated phosphorylation of $\beta$-catenin (17). Serine $33 / 37$ phosphorylation of $\beta$-catenin is mediated by GSK3 $\beta$. Phosphorylation at this site leads to ubiquitination of $\beta$-catenin, which acts as a bridge for proteasomal degradation (18). In addition, it has been reported that serine 552 phosphorylation can facilitate $\beta$-catenin translocation from the cytoplasm to the nucleus (18). The present 
A

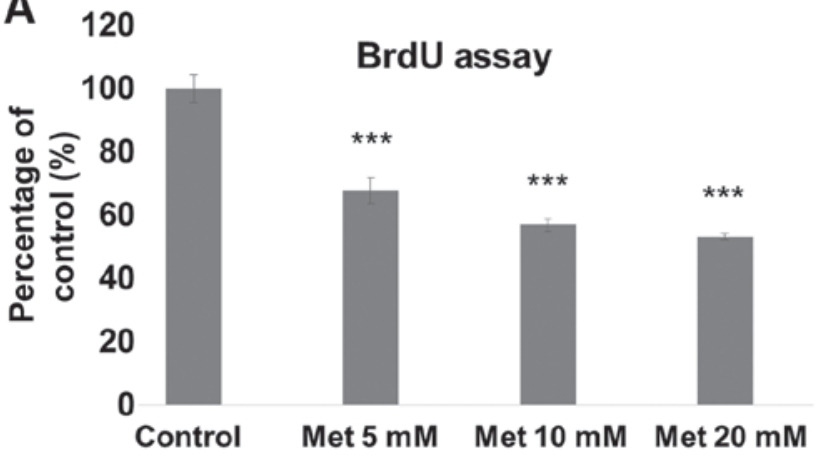

C

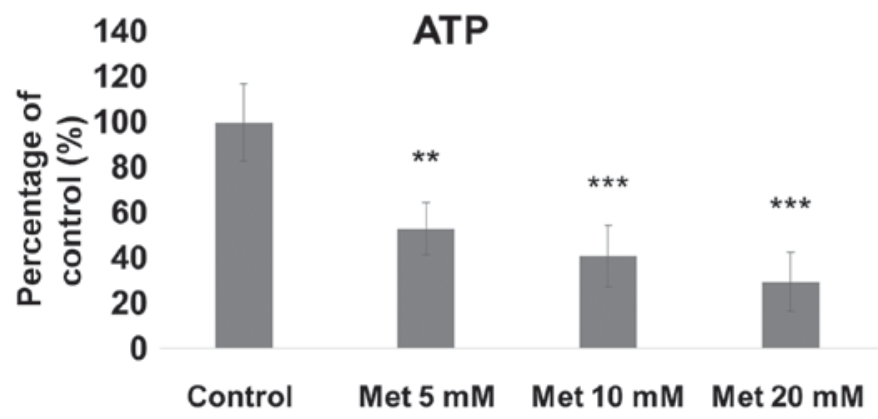

B

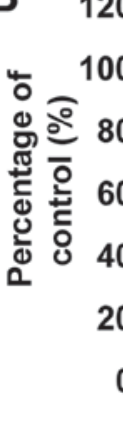

20

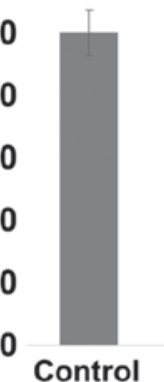

MTT assay

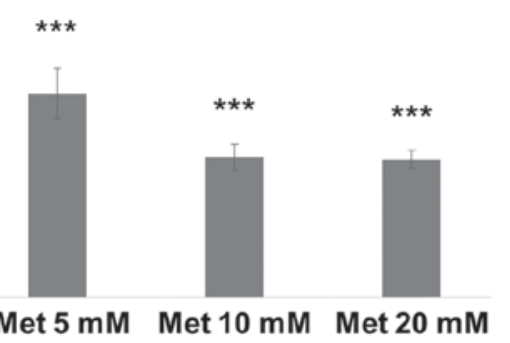

D

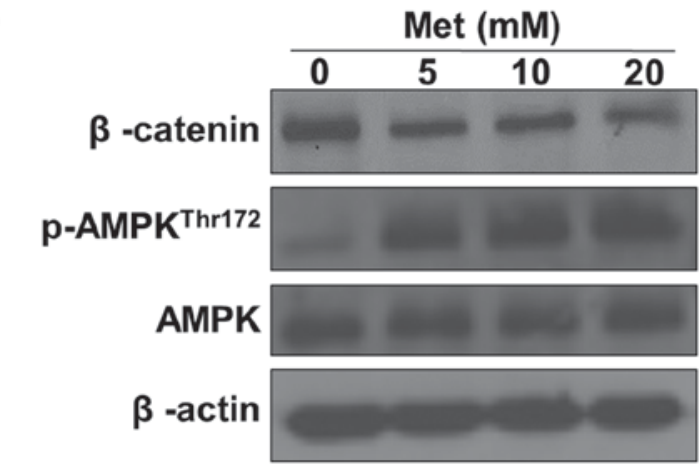

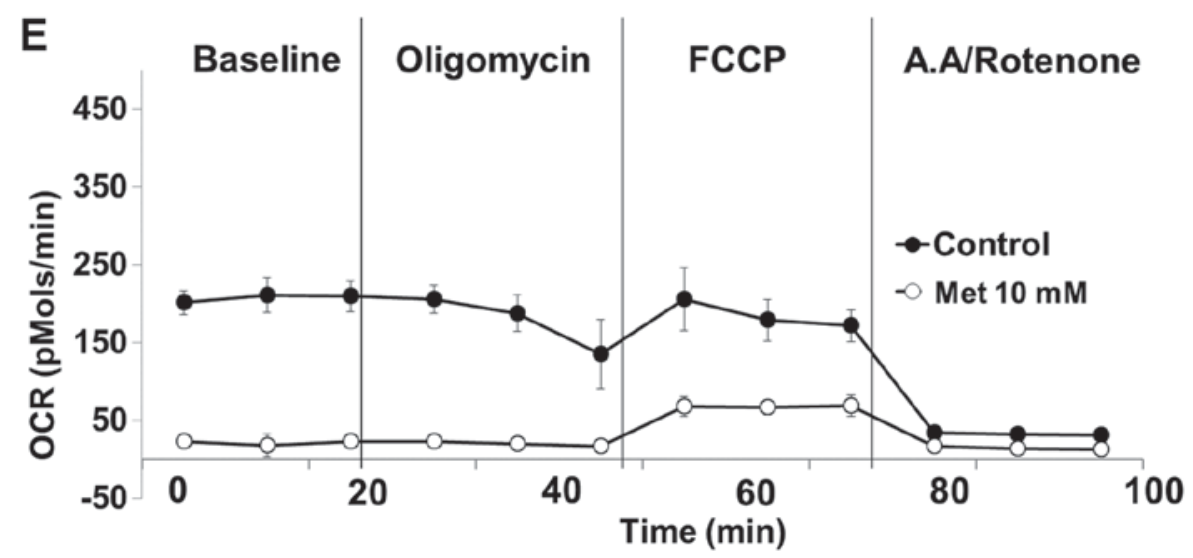

$\mathbf{F}$

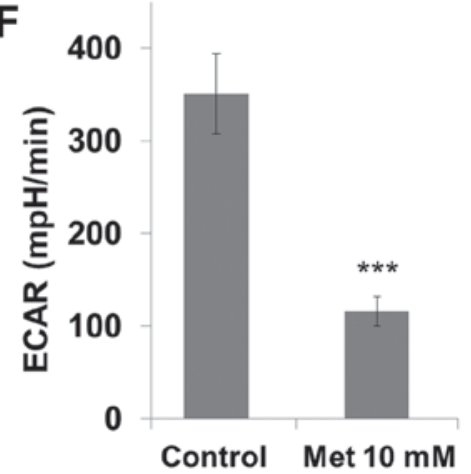

Figure 2. Metformin inhibits cell proliferation and ATP production in RKO cells. Cells were treated with metformin at different concentrations (5-20 mM) for $24 \mathrm{~h}$ and cell viability was measured by (A) BrdU and (B) MTT assay. (C) Cells were subjected to cellular ATP measurement. (D) Cell lysates were subjected to immunoblot analysis for $\beta$-catenin, p-AMPK, AMPK and $\beta$-actin. Cells were plated into XF2 4 culture plates and incubated for $24 \mathrm{~h}$ using a medium containing glucose, glutamine and pyruvate. (E) OCR responses to oligomycin $(2 \mu \mathrm{M})$, FCCP $(0.1 \mu \mathrm{M})$, antimycin $\mathrm{A}(1 \mu \mathrm{M})$ and rotenone $(1 \mu \mathrm{M})$ were measured and (F) the baseline of ECAR was measured. ${ }^{* *} \mathrm{P}<0.01$ and ${ }^{* * *} \mathrm{P}<0.001$ vs. control. p, phosphorylated; AMPK, 5'-adenosine monophosphate-activated protein kinase; ATP, adenosine 5'-triphosphate; OCR, oxygen consumption rate; ECAR, extracellular acidification rate; Met, metformin.

study examined whether the AMPK-mediated decrease in $\beta$-catenin expression may be attributable to proteasomal degradation. In the presence of MG132, metformin still activated AMPK; however, it failed to reduce $\beta$-catenin expression. Instead, a ubiquitination laddering pattern was produced (Fig. 4). Since $\beta$-catenin phosphorylation on residues serine 33/37 was observed in metformin-treated cells, GSK-mediated $\beta$-catenin phosphorylation and subsequent proteosomal degradation may have adequately occurred. In addition, $\beta$-catenin phosphorylation on serine 552 was observed in metformin-treated cells (Fig. 4). These results suggest that an association of $\beta$-catenin with AMPK may sequester $\beta$-catenin in the cytoplasm, even when serine 552 is phosphorylated. This cytoplasmic sequestering of $\beta$-catenin may subject $\beta$-catenin to degradation.
Metformin suppresses $\beta$-catenin-dependent Wnt signaling through AMPK activation. Metformin-induced suppression of cell proliferation was partially restored by inhibition of AMPK using compound C (Fig. 5A). Subsequently, the current study examined whether metformin could suppress RKO cell proliferation and inhibit $\beta$-catenin expression when Wnt signaling was hyperactivated. It was identified that Wnt-treatment increased cell proliferation. This increase in cell proliferation was significantly inhibited by co-treatment with metformin (Fig. 5B). $\beta$-catenin expression was markedly lower in cells co-treated with Wnt and metformin compared with that in cells treated with Wnt alone (Fig. 5C). Wnt treatment did not affect the phosphorylation status of AMPK (Fig. 5C). To determine whether these effects were attributable to AMPK, cells were treated with compound $\mathrm{C}$, an AMPK inhibitor. 
A

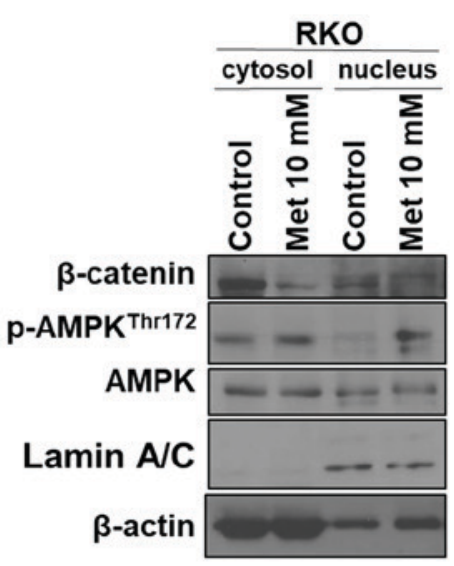

C
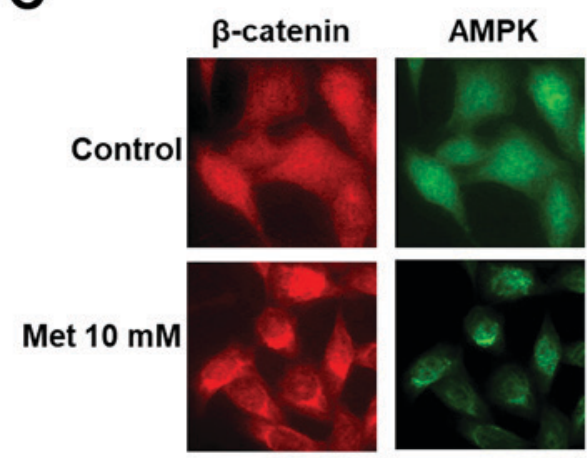
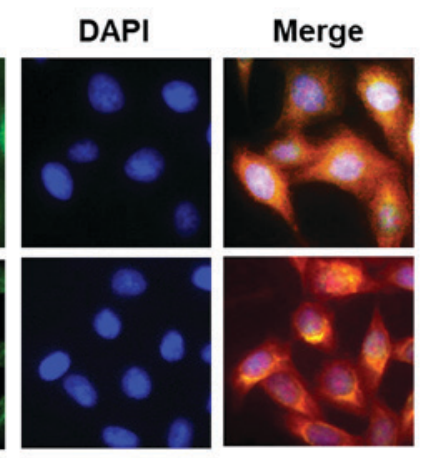

B
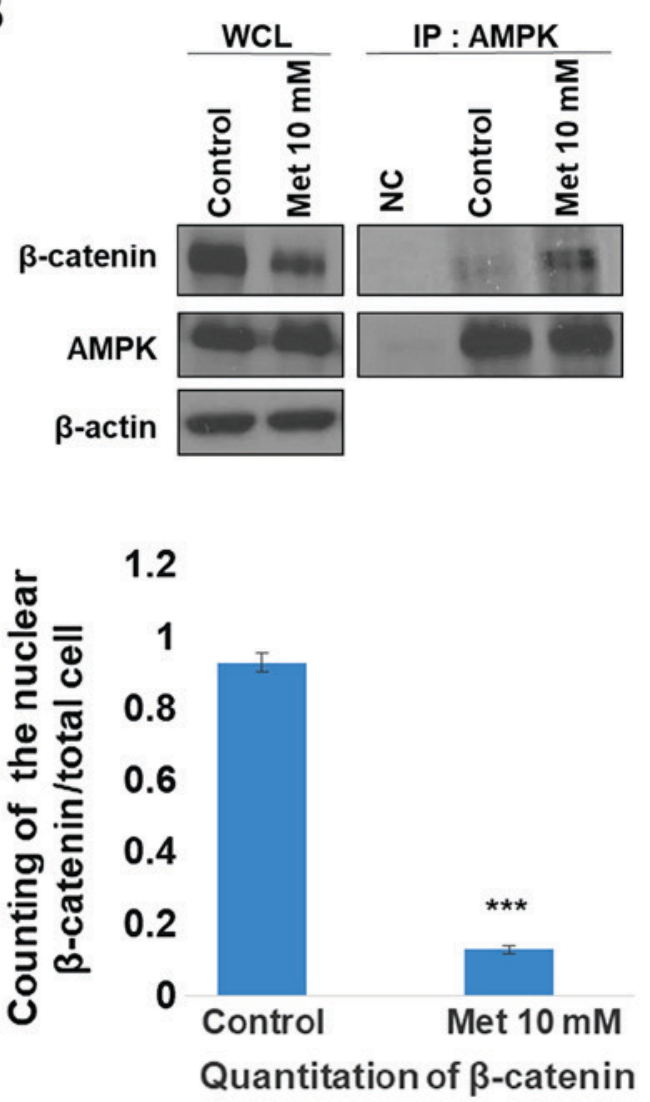

Figure 3. Metformin acts as a negative regulator of $\beta$-catenin translocation into the nucleus. (A) Cells were fractionated into the cytosol and nucleus, and then subjected to immunoblot analysis using the indicated antibodies. (B) Cell lysates were precipitated using an anti-AMPK antibody. Levels of $\beta$-catenin and antibody-bound proteins were measured by immunoblot analysis using anti- $\beta$-catenin and anti-AMPK antibodies. (C) Cells were treated with metformin for $24 \mathrm{~h}$ and subjected to immunofluorescence staining for $\beta$-catenin and AMPK. The number of cells with nuclear $\beta$-catenin was quantified by direct counting. Magnification, $\mathrm{x} 400 .{ }^{* * *} \mathrm{P}<0.001$ vs. control. p, phosphorylated; AMPK, 5'-adenosine monophosphate-activated protein kinase; WCL, whole cell lysate; IP, immunoprecipitation.

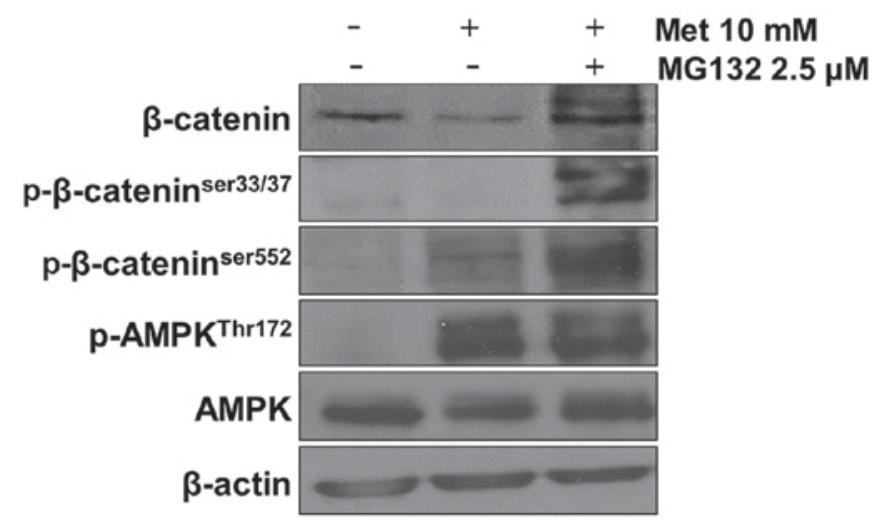

Figure 4. AMPK is associated with $\beta$-catenin degradation. Cells were treated with $10 \mathrm{mM}$ met and $2.5 \mu \mathrm{M}$ MG132 for $24 \mathrm{~h}$. Protein levels of $\mathrm{p}-\beta$-catenin ${ }^{\mathrm{ser} 33 / 37}, \mathrm{p}-\beta$-catenin ${ }^{\mathrm{ser} 552}, \beta$-catenin, $\mathrm{p}-\mathrm{AMPK}^{\mathrm{Thr} 172}$ and AMPK were then examined by immunoblot analysis. met, metformin; ser, serine; Thr, threonine; p, phosphorylated; AMPK, 5'-adenosine monophosphate-activated protein kinase.

The results revealed that the metformin-induced decrease in $\beta$-catenin expression level was restored following treatment with compound $\mathrm{C}$ (Fig. 5D). These results suggest that metformin-induced AMPK activation can regulate $\beta$-catenin expression.

\section{Discussion}

The Wnt pathway is one of the most important signaling pathways with regard to cell survival and differentiation. Overexpression and mutations of proteins associated with the Wnt signaling pathway have been identified in several types of cancer $(19,20)$. Aberrant expression of $\beta$-catenin has been demonstrated in various types of human cancer, including colon cancer. Furthermore, a number of studies have demonstrated that $\beta$-catenin, a transcription factor involved in the Wnt signaling pathway, is frequently upregulated in various types of cancer cells $(21,22)$. $\beta$-catenin exhibits two functions in cells. Firstly, it is responsible for cell-cell adhesion at the cell membrane by binding to E-cadherin. Secondly, it is a transcription factor in the nucleus and serves as the final messenger of the Wnt signaling pathway (23). Therefore, the intracellular $\beta$-catenin expression level is maintained at a certain level. $\beta$-catenin forms a cytoplasmic complex with APC, axin and GSK to maintain these proteins at appropriate levels, which causes ubiquitination and proteasomal degradation of $\beta$-catenin (17).

Numerous studies have reported that AMPK is frequently downregulated in several types of cancer cells (24). AMPK is one of the most important targets of cancer therapy. Evidence suggests that several AMPK activators can suppress cancer 
A

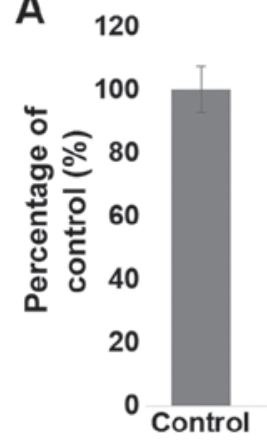

MTT assay

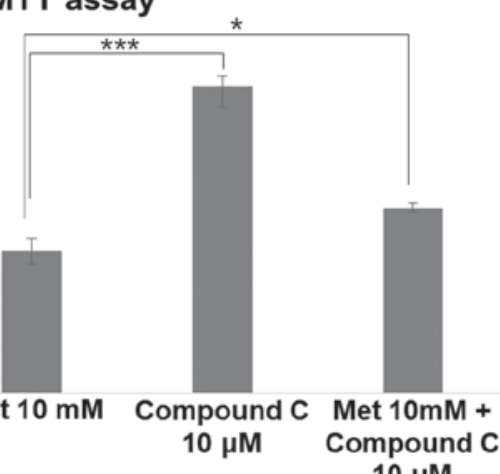

B 180

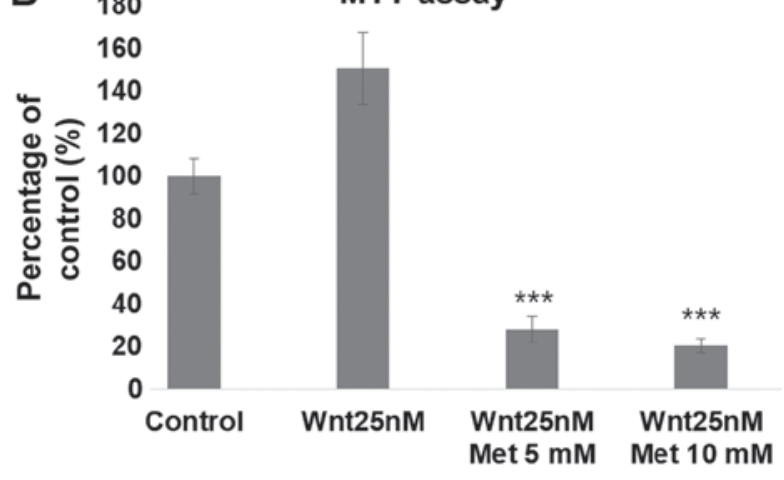

D

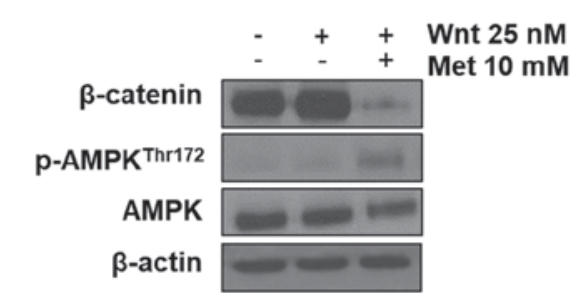

C

Figure 5. AMPK acts as a negative regulator of $\beta$-catenin in metformin-treated RKO cells. (A) Cells were treated with metformin and/or compound $\mathrm{C}$ for $24 \mathrm{~h}$ and cell viability was then measured by MTT assay. ${ }^{*} \mathrm{P}<0.05$ and ${ }^{* * *} \mathrm{P}<0.001$. (B) Cells were treated with metformin and/or Wnt 3 a for $24 \mathrm{~h}$ and cell viability was then measured by MTT assay. ${ }^{* * *} \mathrm{P}<0.001 \mathrm{vs}$. Wnt $25 \mathrm{~nm}$. (C) Cells were treated with $25 \mathrm{nM}$ Wnt3a and $10 \mathrm{mM}$ met for 24 h. Protein levels of $\beta$-catenin, p-AMPK Thr172 and AMPK were examined by immunoblot analysis. (D) Cells were pre-treated with $25 \mathrm{nM}$ Wnt $3 \mathrm{a}$ and then treated with $10 \mu \mathrm{M}$ Compound $\mathrm{C}$ and $10 \mathrm{mM}$ met for $24 \mathrm{~h}$. The protein level of $\beta$-catenin was examined by immunoblot analysis. Thr, threonine; p, phosphorylated; AMPK, 5'-adenosine monophosphate-activated protein kinase; met, metformin.

cell growth and induce apoptosis $(25,26)$. Metformin is known to be an AMPK activator. AMPK is a crucial cellular energy sensor that can increase intracellular AMP level (13). It has been reported that AMPK activation can suppress cancer cell proliferation in various types of carcinoma by inhibiting signaling molecules, including protein kinase B and mTOR, and regulating tumor suppressors, including cellular tumor antigen $\mathrm{p} 53$, which induces cancer cell apoptosis. The present study demonstrated that the activation of AMPK was associated with a reduction in the nuclear $\beta$-catenin expression level, and cell growth was significantly reduced in metformin-treated RKO cells.

The importance of inhibiting the nuclear translocation of $\beta$-catenin has been recognized for suppressing cancer cell proliferation and metastasis (27). A number of reports have suggested that AMPK-regulated genes are associated with Wnt signaling, including GSK3 $\beta$ and Dishevelled $(28,29)$. As chemical activators of AMPK can suppress Wnt3a-induced TCF-dependent transcriptional activity, we hypothesized that AMPK activity may participate in the regulation of Wnt signaling. However, a limited number of studies have investigated the direct association between AMPK and $\beta$-catenin. The current study performed immunoprecipitation and immunofluorescence analysis to identify whether activated AMPK could bind to $\beta$-catenin in metformin-treated RKO cells. The results demonstrated that binding between AMPK and $\beta$-catenin occurred in the cytoplasm near the nuclear membrane. In addition, phosphorylation of the serine 552 residue of $\beta$-catenin was maintained; however, the translocation of $\beta$-catenin to the nucleus was not observed. These results suggest that $A M P K$-inhibited $\beta$-catenin nuclear translocation may be due to cytoplasmic sequestering of $\beta$-catenin through the association with AMPK. Sequestered $\beta$-catenin remains targeted to proteosomal degradation since serine $33 / 37$ residues of $\beta$-catenin are phosphorylated and a ubiquitination laddering pattern was produced when cells were treated with proteasome inhibitor MG132 and metformin. Furthermore, metformin-induced AMPK activation reduced Wnt-mediated cell viability and $\beta$-catenin degradation, suggesting that AMPK activation may regulate Wnt activity. In primary hepatocytes, a lower concentration $(<100 \mathrm{nM})$ of metformin activated AMPK, resulting in suppression of glucose production $(30,31)$. In ovarian cancer cells, $>1 \mathrm{mM}$ metformin demonstrated a growth inhibitory effect, as well as AMPK activation (32). In the present study, with a low dose of metformin, AMPK was weakly activated without an inhibitory effect on cell proliferation, suggesting that a higher level of AMPK activity may be required for the suppression of cell proliferation. In human clinical trials for patients with diabetes, the safety of metformin has been proven and the dose-limiting toxicity of metformin was reported as 2,500 $\mathrm{mg} /$ day (33).

A number of studies have described the ability of metformin to reduce the risk of cancer among patients with metformin-treated diabetes (34-36). Therefore, metformin may be considered as a candidate drug to be used for the prevention of cancer; however, the exact mechanism remains to be elucidated. The current results, which demonstrated that metformin-activated AMPK may be due to mitochondrial dysfunction, suggest that AMPK activity is an important factor for the effects of metformin; however, inhibition of AMPK only partially restored metformin-induced cell death, suggesting that unidentified additional mechanisms may be involved. Although the safety of metformin has been 
demonstrated in diabetes treatment, further studies investigating the complete mechanism of metformin are required, particularly with regard to cancer, prior to clinical trials using the drug.

Metformin can suppress cellular energy production by inhibiting mitochondrial complex I (12). This reduction of cellular energy may promote AMPK activation. In the present results, the baseline OCR of metformin-treated RKO cells was lower compared with that of control RKO cells treated with oligomycin, an inhibitor of mitochondrial complex $\mathrm{V}$, but similar to that of RKO cells treated with rotenone, an inhibitor of mitochondrial complex I. This result is consistent with that of a previous study, which demonstrated that cell proliferation is suppressed in metformin-treated H1299 and HCT116 cells by inhibition of mitochondrial complex I (37). Therefore, mitochondrial dysfunction and reduction of energy production are required for metformin-induced AMPK activation. In addition, Wnt signaling activity is also associated with energy metabolism. Wnt signaling is understood to serve an important role in the survival of cancer cells (38). Wnt signaling increases aerobic glycolysis by transcribing c-myc, which upregulates the expression of glycolytic genes, including glucose transporter-1 and lactate dehydrogenase in cancer cells (39). Axin, a negative regulator for Wnt signaling, can reduce mitochondrial energy metabolism by suppressing mitochondrial complex IV function (40). Considering how AMPK activation inhibits Wnt signaling, reduced Wnt signaling activity may also participate in the regulation of metabolic energy production. This reduced Wnt signaling activity may be an additional mechanism to reduce energy production further in metformin-treated AMPK-activated cells.

In summary, the current study suggests sequential mechanisms are involved in metformin-induced suppression of Wnt signaling and cell proliferation. Metformin treatment suppresses mitochondrial energy metabolism, which activates AMPK. Activated AMPK can sequester $\beta$-catenin in the cytoplasm, which increases $\beta$-catenin proteosomal degradation rather than $\beta$-catenin nuclear translocation. Overall, these events can reduce Wnt signaling activity. Therefore, AMPK is an important regulator of the translocation of $\beta$-catenin from the cytosol into the nucleus to exert anti-proliferative activities with metformin.

\section{Acknowledgements}

Not applicable.

\section{Funding}

This study was supported by the Basic Science Research Program through the National Research Foundation of Korea funded by the Ministry of Education, Science and Technology (grant no. NRF-2015R1D1A1A09056775).

\section{Availability of data and materials}

The datasets used and/or analyzed during the present study are available from the corresponding author on reasonable request.

\section{Authors' contributions}

SYP and SHK designed the experiments. SYP and DK performed the experiments. SYP, DK and SHK analyzed the data. SYP wrote the paper. SHK edited the manuscript. All authors read and approved the final manuscript.

\section{Ethics approval and consent to participate}

Not applicable.

\section{Patient consent for publication}

Not applicable.

\section{Competing interests}

The authors declare that they have no competing interests.

\section{References}

1. Nusse R: Wnt signaling in disease and in development. Cell Res 15: 28-32, 2005.

2. DiMeo TA, Anderson K, Phadke P, Fan C, Feng C, Perou CM, Naber $S$ and Kuperwasser C: A novel lung metastasis signature links Wnt signaling with cancer cell self-renewal and epithelial-mesenchymal transition in basal-like breast cancer. Cancer Res 69: 5364-5373, 2009.

3. Komiya Y and Habas R: Wnt signal transduction pathways. Organogenesis 4: 68-75, 2008.

4. Drees F, Pokutta S, Yamada S, Nelson WJ and Weis WI: Alpha-catenin is a molecular switch that binds E-cadherinbeta-catenin and regulates actin-filament assembly. Cell 123: 903-915, 2005

5. Micalizzi DS, Farabaugh SM and Ford HL: Epithelialmesenchymal transition in cancer: Parallels between normal development and tumor progression. J Mammary Gland Biol Neoplasia 15: 117-134, 2010.

6. Hardie DG, Ross FA and Hawley SA: AMPK: A nutrient and energy sensor that maintains energy homeostasis. Nat Rev Mol Cell Biol 13: 251-262, 2012.

7. Patel VA, Massenburg D, Vujicic S, Feng L, Tang M, Litbarg N, Antoni A, Rauch J, Lieberthal W and Levine JS: Apoptotic cells activate AMP-activated protein kinase (AMPK) and inhibit epithelial cell growth without change in intracellular energy stores. J Biol Chem 290: 22352-22369, 2015.

8. Shaw RJ: LKB1 and AMP-activated protein kinase control of mTOR signalling and growth. Acta Physiol (Oxf) 196: 65-80, 2009.

9. Corradetti MN, Inoki K, Bardeesy N, DePinho RA and Guan KL: Regulation of the TSC pathway by LKB1: Evidence of a molecular link between tuberous sclerosis complex and Peutz-Jeghers syndrome. Genes Dev 18: 1533-1538, 2004.

10. Zulato E, Bergamo F, De Paoli A, Griguolo G, Esposito G, De Salvo GL, Mescoli C, Rugge M, Nardin M, Di Grazia L, et al: Prognostic significance of AMPK activation in advanced stage colorectal cancer treated with chemotherapy plus bevacizumab. Br J Cancer 111: 25-32, 2014

11. Madiraju AK, Erion DM, Rahimi Y, Zhang XM, Braddock DT, Albright RA, Prigaro BJ, Wood JL, Bhanot S, MacDonald MJ, et al: Metformin suppresses gluconeogenesis by inhibiting mitochondrial glycerophosphate dehydrogenase. Nature 510: 542-546, 2014.

12. Viollet B, Guigas B, Sanz Garcia N, Leclerc J, Foretz M and Andreelli F: Cellular and molecular mechanisms of metformin: An overview. Clin Sci (Lond) 122: 253-270, 2012.

13. Yue W, Yang CS, DiPaola RS and Tan XL: Repurposing of metformin and aspirin by targeting AMPK-mTOR and inflammation for pancreatic cancer prevention and treatment. Cancer Prev Res (Phila) 7: 388-397, 2014.

14. Liberti MV and Locasale JW: The warburg effect: How does it benefit cancer cells? Trends Biochem Sci 41: 211-218, 2016.

15. Shang $S$, Hua F and Hu ZW: The regulation of $\beta$-catenin activity and function in cancer: Therapeutic opportunities. Oncotarget 8: 33972-33989, 2017. 
16. Cadigan KM and Waterman ML: TCF/LEFs and Wnt signaling in the nucleus. Cold Spring Harb Perspect Biol 4: pii: a007906, 2012.

17. Stamos JL and Weis WI: The $\beta$-catenin destruction complex. Cold Spring Harb Perspect Biol 5: a007898, 2013.

18. Fang D, Hawke D, Zheng Y, Xia Y, Meisenhelder J, Nika H, Mills GB, Kobayashi R, Hunter T and Lu Z: Phosphorylation of beta-catenin by AKT promotes beta-catenin transcriptional activity. J Biol Chem 282: 11221-11229, 2007.

19. Zhan T, Rindtorff $\mathrm{N}$ and Boutros $\mathrm{M}$ : Wnt signaling in cancer. Oncogene 36: 1461-1473, 2017.

20. Park SY, Lee YK, Lee WS, Park OJ and Kim YM: The involvement of AMPK/GSK3-beta signals in the control of metastasis and proliferation in hepato-carcinoma cells treated with anthocyanins extracted from Korea wild berry Meoru. BMC Complement Altern Med 14: 109, 2014.

21. Chen Z, He X, Jia M, Liu Y, Qu D, Wu D, Wu P, Ni C, Zhang Z, Ye J, et al: $\beta$-catenin overexpression in the nucleus predicts progress disease and unfavourable survival in colorectal cancer: A meta-analysis. PLoS One 8: e63854, 2013.

22. Kraus C, Liehr T, Hülsken J, Behrens J, Birchmeier W, Grzeschik KH and Ballhausen WG: Localization of the human beta-catenin gene (CTNNB1) to 3p21: A region implicated in tumor development. Genomics 23: 272-274, 1994.

23. MacDonald BT, Tamai K and He X: Wnt/beta-catenin signaling: Components, mechanisms, and diseases. Dev Cell 17: 9-26, 2009.

24. Motoshima H, Goldstein BJ, Igata M and Araki E: AMPK and cell proliferation-AMPK as a therapeutic target for atherosclerosis and cancer. J Physiol 574: 63-71, 2006.

25. Li W, Saud SM, Young MR, Chen G and Hua B: Targeting AMPK for cancer prevention and treatment. Oncotarget 6: 7365-7378, 2015.

26. Luo Z, Zang M and Guo W: AMPK as a metabolic tumor suppressor: Control of metabolism and cell growth. Future Oncol 6: 457-470, 2010

27. Jang GB, Kim JY, Cho SD, Park KS, Jung JY, Lee HY, Hong IS and Nam JS: Blockade of Wnt/ $\beta$-catenin signaling suppresses breast cancer metastasis by inhibiting CSC-like phenotype. Sci Rep 5: 12465, 2015.

28. Zhang H, Xue J, Li M, Zhao X, Wei D and Li C: Metformin regulates stromal-epithelial cells communication via Wnt $2 / \beta$-catenin signaling in endometriosis. Mol Cell Endocrinol 413: 61-65, 2015.

29. Markowska A, Pawałowska M, Filas V, Korski K, Gryboś M, Sajdak S, Olejek A, Bednarek W, Spiewankiewicz B, Lubin J and Markowska J: Does metformin affect ER, PR, IGF-1R, $\beta$-catenin and PAX-2 expression in women with diabetes mellitus and endometrial cancer? Diabetol Metab Syndr 5: 76, 2013.

30. Zhou G, Myers R, Li Y, Chen Y, Shen X, Fenyk-Melody J, Wu M, Ventre J, Doebber T, Fujii N, et al: Role of AMP-activated protein kinase in mechanism of metformin action. J Clin Invest 108: $1167-1174,2001$
31. Cao J, Meng S, Chang E, Beckwith-Fickas K, Xiong L, Cole RN, Radovick S, Wondisford FE and He L: Low concentrations of metformin suppress glucose production in hepatocytes through AMP-activated protein kinase (AMPK). J Biol Chem 289: 20435-20446, 2014.

32. Erices R, Bravo ML, Gonzalez P, Oliva B, Racordon D, Garrido M, Ibañez C, Kato S, Brañes J, Pizarro J, et al: Metformin, at concentrations corresponding to the treatment of diabetes, potentiates the cytotoxic effects of carboplatin in cultures of ovarian cancer cells. Reprod Sci 20: 1433-1446, 2013.

33. Chae YK, Arya A, Malecek MK, Shin DS, Carneiro B, Chandra S, Kaplan J, Kalyan A, Altman JK, Platanias L and Giles F: Repurposing metformin for cancer treatment: Current clinical studies. Oncotarget 7: 40767-40780, 2016.

34. Evans JM, Donnelly LA, Emslie-Smith AM, Alessi DR and Morris AD: Metformin and reduced risk of cancer in diabetic patients. BMJ 330: 1304-1305, 2005.

35. Ruiter R, Visser LE, van Herk-Sukel MP, Coebergh JW, Haak HR, Geelhoed-Duijvestijn PH, Straus SM, Herings RM and Stricker BH: Lower risk of cancer in patients on metformin in comparison with those on sulfonylurea derivatives: Results from a large population-based follow-up study. Diabetes Care 35: $119-124,2012$.

36. van Staa TP, Patel D, Gallagher AM and de Bruin ML: Glucose-lowering agents and the patterns of risk for cancer: A study with the General Practice Research Database and secondary care data. Diabetologia 55: 654-665, 2012.

37. Griss T, Vincent EE, Egnatchik R, Chen J, Ma EH, Faubert B, Viollet B, DeBerardinis RJ and Jones RG: Metformin antagonizes cancer cell proliferation by suppressing mitochondrial-dependent biosynthesis. PLoS Biol 13: e1002309, 2015.

38. Li N, Ragheb K, Lawler G, Sturgis J, Rajwa B, Melendez JA and Robinson JP: Mitochondrial complex I inhibitor rotenone induces apoptosis through enhancing mitochondrial reactive oxygen species production. J Biol Chem 278: 8516-8525, 2003.

39. Sherwood V: WNT signaling: An emerging mediator of cancer cell metabolism? Mol Cell Biol 35: 2-10, 2015.

40. Shin JH, Kim HW, Rhyu IJ and Kee SH: Axin is expressed in mitochondria and suppresses mitochondrial ATP synthesis in HeLa cells. Exp Cell Res 340: 12-21, 2016.

This work is licensed under a Creative Commons Attribution-NonCommercial-NoDerivatives 4.0 International (CC BY-NC-ND 4.0) License. 